Rose, R. E. \& Miller, J. G. (1954). J. gen. Microbiol. 10, 1-10.

\title{
Some Sampling Variations in Soil Fungal Numbers
}

\author{
By R. E. ROSE AND JEAN G. MILLER \\ Rukuhia Soil Research Station, Hamilton, and Department of Agriculture, \\ Wellington, New Zealand
}

\begin{abstract}
SUMMARY: Fungal counts (as measured by direct plate counts) from soil samples taken from the same field have frequently shown variations of the order of $1: 13$ for some New Zealand pastures. The main source of error of mean counts is the variation between cores in the field, much less being due to subsampling and plating methods in the laboratory. For an arbitrary standard of accuracy, based on differences observed between soils at various stages of development, about twenty-five cores per field are necessary even if the field appears homogeneous. If the cores are to be bulked before plating thirty-two should be taken, preferably in eight groups of four cores. Little advantage accrues from taking more than three plates per sample for incubating and counting. Wide variations are occasionally obtained between batches on the mechanical shaker, but this could not be attributed to the effect of time of shaking.
\end{abstract}

In the course of some work to determine the average microfloral numbers of some New Zealand soils, large differences were found between counts from samples in the same field. The range of counts was considerably larger than that quoted by Waksman (1931), who found numbers varying from 8 to 25 millions per gram from fifty-one samples taken from a $\frac{1}{20}$ acre plot. This ratio of $1: 3.25$ is often exceeded on apparently uniform pasture, figures of $1: 39(0 \cdot 2-7 \cdot 9$ millions) for actinomycetes, $1: 32(0 \cdot 1-3 \cdot 2$ millions $)$ for bacteria and $1: 13(50,000$ to 641,000$)$ for fungi being not uncommon from plots of $\frac{1}{40}$ acre of pasture. Consequently, Waksman's suggestion of five samples each of three or four borings, which has apparently been followed by other workers, seemed inadequate for New Zealand conditions. To determine the optimum number of samples for the purpose of future comparative studies, a series of trials was planned with soil samples from two different districts.

A. Rotorua district where the soil used for the trial was Taupo sandy silt, a moderately leached yellow brown pumice soil from Taupo ash.

This soil was further subdivided into three categories:

Virgin soil-an area of unused land of about 1 acre in extent was used, the average distance between samples being about $10 \mathrm{ft}$.

New pasture-samples were taken from an area of about 1 acre in a valley from pasture about 2 years old.

Old pasture-a similar area to the above but the pasture was about 15 years old.

The vegetation on the virgin soil area was tussock, with some scrub. The pasture on the other two areas contained ryegrass, white clover and cocksfoot, with some to much Yorkshire fog, some crested dogstail, Poa pratensis and suckling clover. 
B. Rukuhia Soil Research Station, where the soil is Hamilton clay loam, a moderately leached brown granular clay, derived from Hamilton (andesitic) ash.

The pasture sampled was dominantly perennial ryegrass-white clover, dense and evenly grazed, typical of a highly producing sward in the area.

\section{METHODS}

\section{Procedure for collecting samples}

A 1 in. cylindrical soil sampler was used throughout, the 0-3 in. layer being taken and removed and the sampler replaced to take the 3-6 in. layer, when this was required.

From each of the Rotorua soils twenty cores were taken in October 1950. These were each bagged separately, so that a measure of the variation between cores might be obtained. These samples were designated series 1. In June 1951, twenty. cores were taken from each of the same areas and were bulked for each area. Samples were later drawn from these bulks, to determine subsampling variances, and these samples were called series 2 . A repeat test of the bulk soil taken at this sampling time was made for the new pasture only (since the first tests showed some curious results) and results of this test were called series 3.

On the Hamilton soil, the first sampling aimed at establishing the relative variance due to location in the field, and due to the particular cores that were taken at any one site. Hence seven sites were chosen within an area of $\frac{1}{4}$ acre of gently undulating land, and at each site four cores were taken as closely together as possible, each layer of each core being bagged separately. These samples were called Hamilton series 1. On the same date, April 1951, on the same locality, two sets of twenty cores were taken and bulked, each layer being kept separate. This was to determine subsampling variances, and results from samples from these bulks were called Hamilton series 2, lots A and B. The cores comprising lot $\mathbf{A}$ were a short distance away from those comprising lot $\mathbf{B}$, and were slightly farther down the slope.

\section{Procedure for preparation of samples}

For series 1 Rotorua soils each individual sample was sieved (2 mm. sieve) and $10 \mathrm{~g}$. of soil taken for preparing the dilution. In many of the samples there was little more than $10 \mathrm{~g}$. available from each core. For series 2 Rotorua soils the twenty cores yielded the following amount of sieved soil: virgin, $540 \mathrm{~g}$.; new pasture, $205 \mathrm{~g}$; old pasture, $392 \mathrm{~g}$. After sieving and mixing, fifteen samples each of $10 \mathrm{~g}$. were taken for the preparation of dilutions.

For series 1 Hamilton soil, individual samples were sieved and $10 \mathrm{~g}$. taken, this representing about $20 \%$ of the sample.

For series 2 Hamilton soil each bulk was sieved and mixed and fifteen samples each of $10 \mathrm{~g}$. were taken. Each sample in this instance represents about $1 \%$ of the total bulk. 


\section{Plating procedure}

Dilutions for plating were prepared as follows: $(a) 10 \mathrm{~g}$. soil shaken with $100 \mathrm{ml}$. water $=1 / 10$ dilution; $(b) 5 \mathrm{ml}$. of $(a)$ made up to $100 \mathrm{ml}$. and shaken $=1 / 200 ;(c) 1 \mathrm{ml}$. of $(b)$ made up to $100 \mathrm{ml}$. and shaken $=1 / 20,000$.

Each dilution was shaken for 5 min. on a Microid flask shaker.

One ml. of the final dilution was pipetted into a Petri plate and $10 \mathrm{ml}$. of medium held at $48^{\circ}$ poured into the plate and evenly distributed. Standard methods of maintaining sterility were used throughout. Fungi were plated on a medium of the following composition, as used by Jensen (1984) in his investigations: glucose, $10.0 \mathrm{~g}$.; asparagine, $1.0 \mathrm{~g}$.; $\mathrm{KH}_{2} \mathrm{PO}_{4}, \mathbf{2 . 0} \mathrm{g}$.; $\mathrm{MgSO}_{4}$, 0.5 g.; $\mathrm{NaCl}, 0.5 \mathrm{~g}$; agar, $25.0 \mathrm{~g}$; $\mathrm{H}_{2} \mathrm{O}, 1000.0 \mathrm{ml}$; ; adjusted to $\mathrm{pH} \mathrm{4.6-4.8}$ and incubated for 4-5 days before counting.

In series 1 Rotorua soils four parallel plates were prepared from each dilution, for all other series three plates. In Rotorua old pasture, series 1, two plates were spoilt and could not be counted.

\section{Procedure for counting}

Direct counts were made of every colony, and for convenience statistical analyses have been carried out on these numbers. To give numbers of organisms per gram of soil, numbers per plate must be multiplied by the appropriate dilution figure, i.e. $\mathbf{2 0 , 0 0 0}$.

\section{Distribution of counts}

In studying the form of the distribution of the statistical population of fungal numbers as determined by the plate method, the appropriate variate is 'count per plate' of plates from the same soil sample. Although the different series of samples were taken to study different field sampling aspects, they can all be used to give estimates of the variance between plates prepared from the same sample. The estimates quoted for the variance in Table 1 are the values for the 'mean square within samples' from the analysis of variance tables for all soils. No transformation was applied to the variate, and all results are in units of the count per plate.

The agreement in the coefficients of variation for the two or three estimates for each type of soil is good, except possibly for the Rotorua old pasture. If the organisms are distributed among the plates according to a Poisson distribution, the plates variance of any series of samples should be equal to the corresponding mean plate count. A graph of the above values shows all points falling closely about the line 'variance =mean', with the exception of the Rotorua old pasture. A further test of the Poisson distribution hypothesis was made from the two series of samples of the Rotorua virgin soil. In series 1, when one aberrant core was omitted, the mean square between the nineteen remaining core means was less than the 'within cores' mean square, so that the seventy-six plates could be considered as belonging to one population. The $\chi^{2}$ test for the fit of the data to a Poisson distribution gave $\boldsymbol{P}=\mathbf{0} \cdot \mathbf{2 1}$. The graph of the distribution shows that the deviations from the theoretical are 
Table 1. Means and variances between plates for all soils

\begin{tabular}{|c|c|c|c|c|c|c|}
\hline Origin of material & & $\begin{array}{l}\text { Mean } \\
\text { count per } \\
\text { plate }\end{array}$ & $\begin{array}{l}\text { Degrees } \\
\text { of } \\
\text { freedom }\end{array}$ & Variance & $\begin{array}{c}\text { Standard } \\
\text { devia- } \\
\text { tion }\end{array}$ & $\begin{array}{l}\text { Coeff. of } \\
\text { variation } \\
(\%)\end{array}$ \\
\hline Rotorua, virgin soil & $\begin{array}{l}\text { Series } 1 \\
\text { Series } 2\end{array}$ & $\begin{array}{l}7 \cdot 1 \\
5 \cdot 9\end{array}$ & $\begin{array}{r}60 \\
30\end{array}$ & $\begin{array}{l}9.9 \\
8 \cdot 1\end{array}$ & $\begin{array}{l}3 \cdot 2 \\
2 \cdot 8\end{array}$ & $\begin{array}{l}45 \\
47\end{array}$ \\
\hline Rotorua, new pasture & $\begin{array}{l}\text { Series } 1 \\
\text { Series 2 } \\
\text { Series 3 }\end{array}$ & $\begin{array}{l}13 \cdot 9 \\
39 \cdot 4 \\
14 \cdot 5\end{array}$ & $\begin{array}{l}60 \\
30 \\
16\end{array}$ & $\begin{array}{r}10 \cdot 5 \\
46 \cdot 8 \\
9 \cdot 1\end{array}$ & $\begin{array}{l}\mathbf{3 \cdot 3} \\
6 \cdot 8 \\
\mathbf{3 \cdot 0}\end{array}$ & $\begin{array}{l}24 \\
17 \\
21\end{array}$ \\
\hline Rotorua, old pasture & $\begin{array}{l}\text { Series } 1 \\
\text { Series } 2\end{array}$ & $\begin{array}{l}33 \cdot 1 \\
24 \cdot 2\end{array}$ & $\begin{array}{l}\mathbf{5 8} \\
\mathbf{3 0}\end{array}$ & $\begin{array}{l}64 \cdot 0 \\
15 \cdot 2\end{array}$ & $\begin{array}{l}8 \cdot 0 \\
3 \cdot 9\end{array}$ & $\begin{array}{l}24 \\
16\end{array}$ \\
\hline Hamilton, $0-3$ in. & $\begin{array}{c}\text { Series 1 } \\
\text { Series 2, } \\
\text { Lot A } \\
\text { Series 2, } \\
\text { Lot B }\end{array}$ & $\begin{array}{l}27 \cdot 6 \\
24 \cdot 9 \\
31 \cdot 1\end{array}$ & $\begin{array}{l}56 \\
30 \\
30\end{array}$ & $\begin{array}{l}26 \cdot 2 \\
17 \cdot 6 \\
32 \cdot 1\end{array}$ & $\begin{array}{l}4 \cdot 2 \\
5 \cdot 6\end{array}$ & $\begin{array}{l}18 \\
17 \\
18\end{array}$ \\
\hline Hamilton, 3-6 in. & $\begin{array}{c}\text { Series 1 } \\
\text { Series 2, } \\
\text { Lot A } \\
\text { Series 2, } \\
\text { Lot B }\end{array}$ & $\begin{array}{l}16 \cdot 7 \\
17 \cdot 5 \\
24.0\end{array}$ & $\begin{array}{l}56 \\
30\end{array}$ & $16 \cdot 9$ & $4 \cdot 1$ & 25 \\
\hline
\end{tabular}

erratic, and therefore it would be reasonable to expect a better fit if a larger sample were available. Series 2 of the Rotorua virgin soils, which consisted of three plates from each of fifteen subsamples from the one bulk of well-mixed soil was similarly tested and the Poisson distribution fitted with a $\chi^{2}$ probability of $0 \cdot 65$.

Thus the tests agree that the counts per plate can be reasonably considered to show the characteristics of the Poisson distribution. As this is an expected distribution, the technique for plating and counting can therefore be considered satisfactory (Quenouille, 1948). The accuracy of the counts as descriptions of the number of organisms in the field can now be estimated, when the variances associated with each level of the sampling procedure have been ascertained.

\section{Sampling stages and their variances}

In obtaining the material for the plate counts three stages of sampling are normally used: (i) 'sites' are chosen in the field; (ii) at each site one or more cores are removed; (iii) from each core several plates are prepared. There is further sampling in the successive dilutions, but this has not been considered here, all operations being taken as part of the process.

\section{Variance due to cores and sites}

For all the samples except those in the Hamilton series 1, only one core was taken at each 'site' in the field. Hence the variance computed as 'between cores' includes the component of 'sites variance' also. One estimate of the two components separately is obtained later.

The estimates of this 'variance between cores' are shown in Table 2. For the Rotorua virgin soil, for which the fit of the Poisson was described above, 
all twenty cores were used in this estimation and the inclusion of the one discrepant core meant that the estimate of core variance component was positive, though small. The term standard deviation in that table is used to indicate the square root of the cores variance component. A graph of the above standard deviations (against the corresponding mean plate counts) shows them to lie approximately along a straight line, with no marked deviations. This indicates that although the number of degrees of freedom available for the estimation is in each case rather small, there is no evidence that any estimate is a 'freak' one which should not be used in further calculations.

Table 2. Estimates of components of cores variance

$\quad$ Origin of material
Rotorua virgin soil series 1
Rotorua new pasture series 1
Rotorua old pasture series 1
Hamilton, $0-3$ in. series 1
Hamilton, 3-6 in. series 1

Comparison of the cores variances in Table 2 with the plates variances in Table 1 shows that for each case except Rotorua virgin soil the cores variance is much higher than the plates variance. Now, one of the limiting factors to the amount of microbiological investigation that can be undertaken by a laboratory is the number of plates to be counted at one time. It is also desirable to keep the number of plates as small as possible on account of the amount of labour and time required for their preparation and the limitations in space for incubation. Consequently, a sampling scheme must be chosen to give the greatest amount of information from the fewest number of plates. In view then of the relative sizes of the 'plates' and 'cores' variance in general, the most efficient sampling scheme will use the fewest number of plates per core. Because accidents are liable to happen to the plates, such as complete overgrowth by a different organism which prohibits counting, the minimum practical number would be three per core. The variance of the mean counts of different cores would then be: var. $_{C}+\frac{1}{3}$ var. ${ }_{P}$, where var. $_{C}$ is cores variance, var. $P$ is plates variance, and the s.E. per core is the square root of this variance.

Since the distribution of plate counts has been established as a Poisson, the

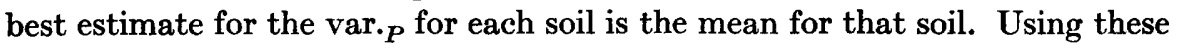
values, the standard errors per core are shown in Table 3 for this series of soils in units of one plate.

Table 3. Estimates of standard errors of mean counts per core, from three parallel plates for each

Soil

Rotorua virgin soil Rotorua new pasture

Rotorua old pasture

Hamilton, $0-3$ in.

Hamilton, 3-6 in.
Variance per core

$6 \cdot 2$

$31 \cdot 7$

$255 \cdot 0$

$224 \cdot 0$

$93 \cdot 6$
Standard

error per core

$2 \cdot 6$
$5 \cdot 7$
$16 \cdot 0$
$15 \cdot 0$
$9 \cdot 7$


From these standard errors can be calculated the number of cores required for any given degree of accuracy. No standard of accuracy can be finally chosen until there is some knowledge of the variations in mean counts which could be expected in the same soil between different sampling times when no progressive change has been taking place. A knowledge of the difference in fungal counts as related to differences in production level is also necessary. An arbitrary decision was made on the differences that would be required to be measured in future work, for each of the soil conditions. The number of cores is then calculated so that, if the variance remains the same as in the present investigation, then it is expected that any measured differences which are as great as those specified differences will be judged statistically significant. The formula for calculating the required number of cores must then be

$$
r=\frac{2 \times \text { variance per core }}{\text { (required difference })^{2}} \times t^{2}
$$

where $t$ is the usual tabulated 'Student's $t$ ', for the probability level at which it is desired to test the hypotheses under investigation. The results of this calculation for all the soils studied, for values of $t$ corresponding to the $5 \%$ probability level are shown in Table 4. These indicate that in the present state of knowledge a working standard of twenty to twenty-five cores should be adopted.

Table 4. Numbers of cores required for the adopted standards of accuracy

$\begin{array}{lccc}\text { Soil } & \text { Mean count } & \begin{array}{c}\text { Difference to } \\ \text { be measured }\end{array} & \begin{array}{c}\text { Number of } \\ \text { cores required }\end{array} \\ \text { Rotorua virgin } & 7 \cdot 1 & 2 & 15 \\ \text { Rotorua new pasture } & 13 \cdot 9 & 4 & 17 \\ \text { Rotorua old pasture } & 33 \cdot 1 & 10 & 22 \\ \text { Hamilton, 0-3 in. } & 27 \cdot 6 & 10 & 31 \\ \text { Hamilton, 3-6 in. } & 16 \cdot 7 & 6 & 23\end{array}$

\section{Location of sampling positions in the field}

The above results were obtained from single cores taken at random over the field. To test the effect of taking larger cores, or of group sampling, one trial was conducted at Hamilton (series 1), where four almost contiguous cores were taken at each 'site' in the field. Samples were taken at two depths and from results of these the components of variance of the sites in the field and of the cores were estimated. The taking of larger cores will not necessarily give the same results as cluster sampling. However, in this trial the cores were taken so closely together that they may almost be considered to form one large core.

$\begin{array}{lccc}\text { Variance } & \text { Variance } \\ \text { due to cores } & \text { due to sites } & \begin{array}{c}\text { Mean count } \\ \text { per core }\end{array} \\ \text { 0-3 in. layer } & 284 & 54 & \mathbf{2 7 \cdot 6} \\ \text { 3-6 in. layer } & \mathbf{3 6} & 52 & \mathbf{1 6 \cdot 7}\end{array}$

Apparently for the 3-6 in. layer considerable accuracy will be lost by taking several cores at one site, since the sites variance is larger than that due to cores. For the 0-3 in. layer, however, the sites variance contributes only a small 
amount to the total, and accordingly much inconvenience may be avoided, with little loss of accuracy by taking the cores in clusters. However, this one trial does not supply sufficient consistent evidence for cluster sampling to be recommended.

\section{Bulking of samples before plating}

For most of this technique investigation, the total amount of soil in each core was used in making the first dilution and its identity kept separate. For routine testing, however, it is envisaged that the required number of samples will be taken from the field then bulked in groups, and one sample will be drawn from each bulk for plating. Only a few degrees of freedom will then be available for estimating the error variance, but if this proves to be in agreement with expectation, as indicated by these individually plated samples, the mean count can be credited with a standard error based on the number of cores taken and not on the small number of subsamples actually planted. The means will then, however, have another component of error, due to subsampling from the bulk, as only a fraction of the soil will be used in making up a dilution. In order to estimate this component, twenty cores were taken from each of the soils. These were bulked and the bulks were thoroughly sieved and mixed. From each bulk fifteen subsamples were drawn and three plates made from each subsample.

Table 5. Components of sub-sampling variance

\section{Soils}

Rotorua virgin series 2

Rotorua new pasture series 2

Rotorua new pasture series 3

Rotorua old pasture series 2

Hamilton, $0-3$ in. series 2, lot $A$

Hamilton, 0-3 in. series 2, lot $B$

Hamilton, 3-6 in. series 2, lot A

Hamilton, 3-6 in. series 2, lot B
Variance comp.
of subsampling

$0 \cdot 0$

$492 \cdot 0$

$3 \cdot 1$

$7 \cdot 5$

$7 \cdot 2$

$21 \cdot 7$

$8 \cdot 7$

$9 \cdot 8$

\section{Variance of plates}

$8 \cdot 1$
$46 \cdot 8$
$9 \cdot 1$
$15 \cdot 2$
$32 \cdot 1$
$16 \cdot 9$
$15 \cdot 8$
$27 \cdot 5$

Mean count

$5 \cdot 9$

$39 \cdot 4$

14.5

$24 \cdot 2$

$24 \cdot 8$

$31 \cdot 1$

$17 \cdot 5$

$24 \cdot 0$

As the bulk of soils from which the samples are drawn is a finite amount, not infinite as in a field, the error per subsample, due to the subsampling process, is given by $\sqrt{ }\left[\operatorname{var}_{s}(1-f)\right]$, where var. $s$ is the subsampling variance and $f$ is the fraction of the total bulk taken in each sample.

Thus the full error variance of a mean count derived from $n$ cores which are bulked into $q$ groups from each of which one sample is taken to give $r$ plates, is

$$
\frac{\operatorname{var}_{\cdot} C}{n}+\frac{\operatorname{var}_{\cdot S}(1-f)}{q}+\frac{\text { var. }_{P}}{q r},
$$

where $\operatorname{var}_{\cdot C}$ is variance component of cores, var. ${ }_{S}$ is variance component of subsampling, var. $_{P}$ is variance component of plates.

The values of the expected standard error per mean count from the soils under consideration were then calculated under the assumption of a sample of twenty-five cores being taken, these cores then being grouped into five bulks from each of which three plates would be prepared. From measurements of 
the soil volume weights the following values of ' $f$ ', the fraction of the bulk which would be taken in the sample, were found to be:

$\begin{array}{lll}\text { Rotorua virgin soil } & f=0.07 & 1-f=0.93 \\ \text { Rotorua new pasture } & f=0.20 & 1-f=0.80 \\ \text { Rotorua old pasture } & f=0.10 & 1-f=0.90 \\ \text { Hamilton 3-6 in. (A \& B) } & f=0.01 & 1-f=0.99\end{array}$

Then the estimations for the standard errors would be as follows:

\begin{tabular}{ll}
\multirow{2}{*}{ Soil } & \multicolumn{2}{c}{ Contributions to variance } \\
Rotorua virgin & $\frac{4 \cdot 0}{25}+\frac{0.93 \times 0 \cdot 0}{5}+\frac{8 \cdot 1}{15}=0 \cdot 16+0 \cdot 0+0 \cdot 54=0 \cdot 70$ \\
New pasture & $\frac{27 \cdot 1}{25}+\frac{3 \cdot 1 \times 0.80}{5}+\frac{9 \cdot 1}{15}=1 \cdot 08+0 \cdot 49+0 \cdot 61=2 \cdot 18$ \\
Old pasture & $\frac{243 \cdot 0}{25}+\frac{7 \cdot 5 \times 0.90}{5}+\frac{15 \cdot 2}{15}=9 \cdot 72+1 \cdot 35+1 \cdot 00=12 \cdot 07$ \\
Hamilton (A and B) & $\frac{88 \cdot 0}{25}+\frac{9 \cdot 0 \times 0.99}{5}+\frac{20 \cdot 0}{5}=3 \cdot 52+1 \cdot 80+1 \cdot 33=6 \cdot 65$
\end{tabular}

The subsampling from bulks has added appreciably to the error in most cases, and it would appear to be worth while to increase the number of bulks. This will have an effect on both the second and third components as they contain the number $q$ in the denominator, so that an effective decrease could be obtained by increasing $q$ to about 8 . That is, a sampling scheme of twentyfour cores grouped into eight bulks would be adequate, while an increase to thirty-two cores grouped in fours would be more likely to give the required standard of accuracy with little increase in the work.

If this bulk method of testing is adopted, then in some circumstances the estimates of the variance components found in this paper can be used to give more accurate estimates of the standard errors of the mean counts than can be obtained from use of the results in the new test.

Thus, if thirty-two cores are taken, and are bulked in lots of four from each of which one subsample is drawn and three plates made, a set of eight mean counts, one per bulk will be obtained. If these are $x_{1} \ldots x_{8}$, the mean square between bulk means will be, in units of one plate count $\frac{3}{7} \Sigma\left(x_{i}-\bar{x}\right)^{2}=A$ and the standard error of the field mean count would be calculated $\sqrt{ }\left(\frac{1}{24} A\right)$.

However, if it can be shown that the variances are of the same order as those in this present investigation then the variance estimates, shown in these tables, being based on more degrees of freedom, will give a better estimate of the total standard error. The mean square $A$ has expectation var. ${ }_{P}+3$ var. $_{.}+3$ var. $_{B}$ (where var. ${ }_{P}$ and var..$_{S}$ are as before and var. $_{{ }}$is the variance due to bulks), and since each bulk consists of four cores taken at random var. ${ }_{B}=\frac{1}{4}$ var. ${ }_{C}$. Now the mean square between plates has expectation var. $P$ and hence (mean square between bulks (i.e. $\boldsymbol{A}$ ) - mean square between plates) has expectation 3 var. $_{S}+\frac{3}{4}$ var. $_{C}$. Now if this quantity as calculated from the values in 
Tables 2-5 agrees with the observed difference of the mean squares, it can be assumed that the same conditions exist at the 2 times of sampling, and hence the tabled values can be used for insertion in the formula (1), which then becomes

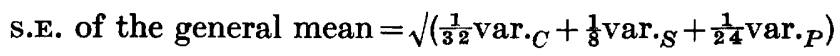

The factor $(1-f)$, for sampling from a finite population must of course be used with the subsampling variance throughout the above calculations wherever the amount taken in the subsample becomes an appreciable amount of the bulk.

\section{Preparation of plates}

When estimates of the subsampling variance were being obtained it was noticed that the subsampling mean square for Rotorua new pasture was very large (being 492). An examination of the counts showed a clear subdivision into groups of four samples which coincided exactly with the groups which were put on the mechanical shaker. When the variance due to 'shakings' was removed the mean square between samples was redued to $6 \cdot 3$. The only other time when this effect could be detected was in the Rotorua old pasture, where it was slight. A repeat test was made from the same bulk of Rotorua new pasture soil, and this, shown as series 3 , did not show the effect at all, besides giving a value for the mean count more in line with series 1 . This test was taken as the correct one, and was used in estimating the error due to subsampling for this soil.

An investigation was made into the effects of different shaking times. A set of sixteen samples (from the same soil) was prepared and was put on to the shaker in subsets of four, and given widely different shaking times. Results are shown in Table 6.

Table 6. Mean counts for different shaking times

$\begin{array}{cc}\begin{array}{c}\text { Shaking time } \\ \text { (min.) }\end{array} & \begin{array}{c}\text { Mean count } \\ \text { per plate }\end{array} \\ 2 \frac{1}{2} & 9 \cdot 7 \\ 5 & 14 \cdot 4 \\ 10 & 16 \cdot 4 \\ 20 & 13 \cdot 2\end{array}$

The differences just fail to reach significance level when tested against the variance of individual sample means, and are certainly not of the order which was encountered in the suspect Rotorua new pasture series. The sample means, however, showed significant differences among themselves when tested against the plates variance. A more complete investigation of this point may be undertaken later.

\section{DISCUSSION}

The sampling scheme which has been proposed for New Zealand soils will measure with accuracy differences in fungal numbers such as have been shown to exist here between undeveloped lands and high-producing pastures. The variability in the higher producing pastures is greater than that of virgin soils 
and apparently of arable land, and this may be due to the effects of the grazing animals. However, it will still be possible with the facilities of a small laboratory to obtain accurate mean values for fields under study provided sufficient field samples are taken.

The mean values of counts in Table 1 for the same soils at different samplings give an indication that seasonal and even diurnal changes may be relatively large, and sampling schemes may have to consider this factor also. The ultimate aim of these laboratory investigations is to trace the changes in soil microflora associated with treatments which change the production level. Differences in physiological groups and types of organisms are as important as changes in numbers, but a sample which gives a satisfactory estimate of numbers is necessary before changes in kind can be studied.

\section{REFERENCES}

Jensen, H. L. (1934). Contributions to the microbiology of Australian soils. Proc. Linn. Soc., N.S.W. 60, 145.

Quenouille, M. H. (1948). Statistical note to 'A technique for the quantitative estimation of soil micro-organisms'. J. gen. Microbiol. 2, 65.

Waksman, S. A. (1931). Principles of Soil Microbiology, 2nd ed. London: Baillière, Tindall and Cox. 